\title{
Controle da ferrugem asiática e produtividade da soja após pulverizações de piraclostrobina + epoxiconazole em diferentes estádios fenológicos da cultura
}

\author{
Mário Henrique Ferreira do Amaral Dal Pogetto ${ }^{1}$, Carlos Gilberto Raetano ${ }^{1}$, Rafael de Souza Christovam ${ }^{1}$, Evandro \\ Pereira Prado ${ }^{1}$, Hélio de Oliveira Aguiar Júnior ${ }^{1}$, Marcelo Júnior Gimenes ${ }^{1}$
}

\begin{abstract}
${ }^{1}$ Faculdade de Ciências Agronômicas, UNESP, CEP 18610-307, Botucatu - SP.
Autor para correspondência: Mário Henrique Ferreira do Amaral Dal Pogetto (mhpogetto@gmail.com)

Data de chegada: 16/02/2012. Aceito para publicação em: 23/04/2012.
\end{abstract}

\section{RESUMO}

Dal Pogetto, M.H.F.A.; Raetano, C.G.; Christovam, R.S.; Prado, E.P.; Aguiar Júnior, H.O.; Gimenes, M.J. Controle da ferrugem asiática e produtividade da soja após pulverizações de piraclostrobina + epoxiconazole em diferentes estádios fenológicos da cultura. Summa Phytopathologica, v.38, n.3, p.248-250, 2012.

Foi avaliado o desenvolvimento da ferrugem asiática e da produtividade da cultura da soja em razão de pulverizações fungicidas realizadas em diferentes estádios fenológicos da cultura. Os tratamentos consistiram na pulverização da mistura fungicida piraclostrobina + epoxiconazole no estádio fenológico $\mathrm{V}_{10}$ e $\mathrm{R}_{2} ; \mathrm{R}_{2}$ e $\mathrm{R}_{5,2}$; apenas em $\mathrm{R}_{2}$; sem pulverização (testemunha). Os valores da AACPD total (área abaixo da curva de progresso da doença) e da produtividade da cultura da soja nos tratamentos com pulverização fungicida foram superiores ao tratamento testemunha. Até o $117^{\circ}$ dia após a emergência das plantas, a aplicação de fungicida em $V_{10}$ e $R_{2}$ promoveu maior controle da ferrugem. Os resultados evidenciaram que a pulverização fungicida contra $P$. pachyrhizi é indispensável para diminuir as perdas na produtividade provocadas pela doença e que, em algumas situações, apenas uma pulverização fungicida no estádio $R_{2}$ pode reduzir perdas significativas na produtividade.

Palavras-chave adicionais: Phakopsora pachyrhizi, momento de aplicação, controle químico

\begin{abstract}
Dal Pogetto, M.H.F.A.; Raetano, C.G.; Christovam, R.S.; Prado, E.P.; Aguiar Júnior, H.O.; Gimenes, M.J. Asian soybean rust control and soybean yield after pyraclostrobin + epoxiconazole spraying in different phenological growth stages. Summa Phytopathologica, v.38, n.3, p.248$250,2012$.

This study evaluated the development of Asian soybean rust and soybean yield after fungicide spraying in different phenological growth stages. Treatments consisted of spraying the fungicide mixture pyraclostrobin + epoxiconazole in the phenological stages $\mathrm{V}_{10}$ and $\mathrm{R}_{2}$; $\mathrm{R}_{2}$ and $\mathrm{R}_{5.2}$; only in $\mathrm{R}_{2}$; and no spraying (control). The total values of AUDPC (area under the disease progress curve) and soybean yield for

treatments with fungicide spraying were superior to those of control. Until the $117^{\text {th }}$ day after emergence, fungicide spraying in $V_{10}$ and $R_{2}$ led to higher rust control. The results evidenced that fungicide spraying against $P$. pachyrhizi is essential to reduce losses in soybean yield caused by the disease and in some situations only one fungicide spraying in $R_{2}$ stage can reduce significant yield losses.
\end{abstract}

Additional keywords: Phakopsora pachyrhizi, spraying schedule, chemical control

A ferrugem asiática da soja (FAS) causada pelo fungo Phakopsora pachyrhizi Sydom \& Sydom desde a sua introdução no Brasil na safra 2001/02 (8) até a atualidade vem ocasionando perdas significativas de produtividade em todas as regiões de cultivo da soja. Embora haja pesquisadores investigando a resistência genética contra $P$. pachyrhizi $(2,14)$ ainda não estão disponíveis cultivares resistentes a todas as raças desse fungo $(3,9)$ sendo o controle através de pulverizações com fungicidas ainda a alternativa mais viável na redução das perdas de produtividade (10).

Diversos trabalhos relatam o alto potencial da FAS em proporcionar reduções de produtividade na cultura da soja. Cunha et al. (6) observaram reduções na produtividade de $61 \%$, Prado et al. (12) de 37\%; Christovam et al. (5) de 49\% e Aguiar-Júnior et al. (1) de 60\%.
Outro fator que merece atenção no controle da FAS é o momento ideal para a realização da primeira aplicação do fungicida, sendo as pulverizações realizadas preventivamente ou imediatamente após a detecção dos primeiros sintomas da doença as mais eficientes (11).

Visto o potencial de P. pachyrhizi em reduzir a produtividade da cultura da soja e buscando esclarecimentos quanto ao número de aplicação e o estádio fenológico da realização do controle da doença, este trabalho teve como objetivo avaliar o desenvolvimento da ferrugem asiática e produtividade da cultura da soja em razão de pulverizações fungicidas realizadas em diferentes estádios fenológicos da cultura.

O experimento foi conduzido na área experimental da Faculdade de Ciências Agronômicas da UNESP, campus de Botucatu em cultura de soja cultivar Conquista, semeada em espaçamento de $0,45 \mathrm{~m}$ e 
densidade de 18 sementes por metro, na safra agrícola 2008/2009. O ensaio foi composto por quatro tratamentos que consistiram na pulverização da mistura comercial do fungicida piraclostrobina + epoxiconazole $\left(66,5+25\right.$ g i.a"'ha $\left.{ }^{-1}\right)$ nos estádios fenológicos, $V_{10}(82$ dias após a emergência - DAE) e $\mathrm{R}_{2}(95 \mathrm{DAE}) ; \mathrm{R}_{2}$ (95 DAE) e $\mathrm{R}_{5.2}(113$ DAE); apenas no estádio $R_{2}(95 \mathrm{DAE})$; sem pulverização (testemunha). O delineamento experimental adotado foi blocos ao acaso, com cinco repetições. As dimensões das parcelas experimentais foram de $5 \times 7 \mathrm{~m}$, totalizando $35 \mathrm{~m}^{2}$. A pulverização da calda fungicida foi realizada com o auxilio de pulverizador costal de barras, pressurizado por $\mathrm{CO}_{2}$ e provido de seis pontas de pulverização de jato plano AXI 110015 , espaçadas de $0,5 \mathrm{~m}$. A pressão de trabalho utilizada foi de $207 \mathrm{kPa}$ produzindo gotas finas com velocidade de deslocamento de $4,0 \mathrm{~km} \cdot \mathrm{h}^{-1} \mathrm{e}$ volume de aplicação de $150 \mathrm{~L} \cdot \mathrm{ha}^{-1}$

A severidade da doença foi avaliada de forma visual através da escala diagramática proposta por Godoy et al. (8), expressa em porcentagem de área foliar lesionada pela doença em quinze folhas retiradas ao acaso do terço médio das plantas de soja. Foram realizadas cinco avaliações em intervalos semanais $(96,103,110,117$ e 124 DAE). Os valores referentes à porcentagem de área foliar lesionada foram utilizados para o cálculo da área abaixo da curva de progresso da doença (AACPD) (4). A produtividade da cultura foi obtida pela colheita mecanizada de $5 \mathrm{~m}$ de três linhas centrais de cada parcela com o auxílio de colhedora de parcelas (Wintersteiger, modelo Seedmech), com a umidade dos grãos corrigida para $13 \%$.

A normalidade dos valores da AACPD foi verificada pelo Teste de Lilliefors $(\mathrm{p}<0,05)$ e as médias dos tratamentos submetidas à análise de variância não-paramétrica e comparadas pelo Teste de Friedman $(\mathrm{p}<0,05)$. A produtividade dos tratamentos foi submetida à análise de variância e as médias comparadas pelo Teste de Tukey $(p<0,05)$. As condições ambientais registradas no momento de cada pulverização variaram de: $1 \mathrm{a} 13 \mathrm{~km} \cdot \mathrm{h}^{-1}$, para a velocidade do vento; $21^{\circ} \mathrm{C}$ a $32{ }^{\circ} \mathrm{C}$ para a temperatura; $70 \%$ a $85 \%$ para a umidade relativa do ar.

A pulverização realizada no estádio $\mathrm{V}_{10}$ da cultura ocorreu de forma preventiva, pois não foi detectada a presença da doença no momento da aplicação. Neste tratamento a severidade da ferrugem asiática foi significativamente inferior ao tratamento testemunha em todas as avaliações, indicando que o produto afetou o desenvolvimento inicial da doença (Tabela 1). Nos demais tratamentos, onde a pulverização fungicida ocorreu depois do estabelecimento da doença, a severidade da ferrugem foi significativamente inferior ao tratamento testemunha somente na última avaliação (124 DAE). Na somatória dos valores da AACPD os tratamentos fungicidas não diferiram significativamente entre si, apenas do tratamento testemunha. Estes resultados indicaram que uma ou duas pulverizações realizadas entre os estádios $\mathrm{V}_{10}$ e $\mathrm{R}_{5.2}$ proporcionaram igual rendimento de controle da doença até o $124^{\circ}$

Tabela 1. Valores da AACPD da ferrugem asiática em função da pulverização fungicida em diferentes estádios fenológicos da cultura da soja.

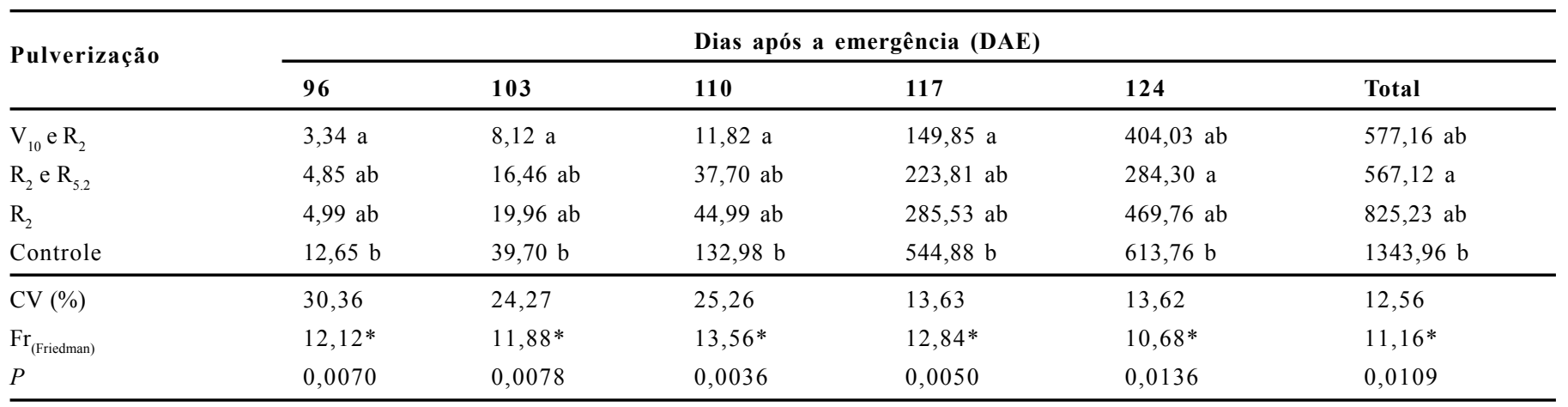

Letras iguais na mesma coluna não diferem pelo Teste de Friedman $(\mathrm{p}<0,05)$.

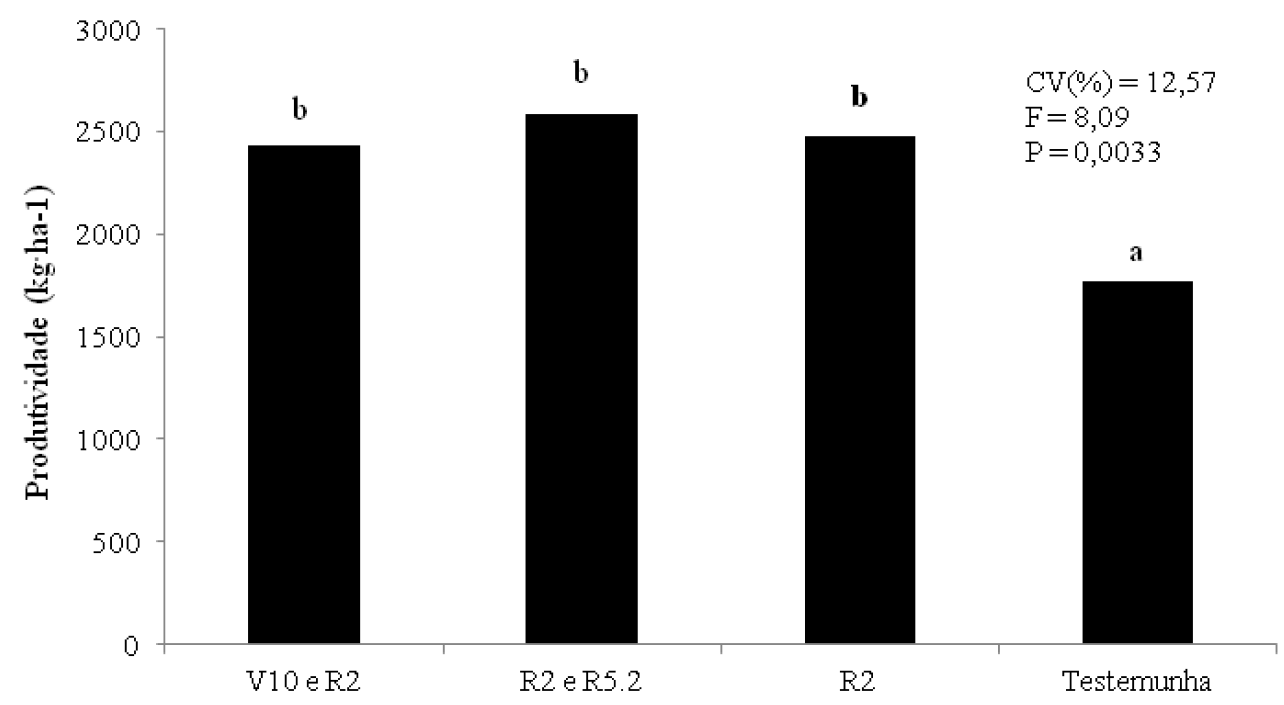

Figura 1. Produtividade da cultura da soja em função da pulverização fungicida em diferentes estádios fenológicos da cultura. Letras iguais não diferem pelo Teste de Tukey $(\mathrm{p}<0,05)$. 
DAE, sendo reforçados pelos valores da produtividade da cultura, que foi significativamente superior nos tratamentos que receberam aplicação de fungicida. (Figura 1). Em pesquisa semelhante, a aplicação de piraclostrobina + epoxiconazole durante o estádio de desenvolvimento $\mathrm{V}_{7}$ da cultura da soja variedade BRS 133 proporcionou menor severidade da ferrugem da soja aos 41 dias após a pulverização em relação às pulverizações realizadas nos estádios $\mathrm{V}_{9}$, $\mathrm{R}_{2}$ e $\mathrm{R}_{5.1}, \mathrm{R}_{5.1}$ e testemunha, mas sem influenciar a produtividade (13). Em contrapartida, na cultivar BRS 154 a severidade da ferrugem foi significativamente menor e a produtividade de grãos de soja significativamente maior com pulverizações da mistura fungicida azoxistrobina + ciproconazole nos estádios de desenvolvimento $\mathrm{R}_{2} \mathrm{e}$ $\mathrm{R}_{5.1}$ (7).

A utilização dos estádios fenológicos da cultura da soja como referência para a pulverização fungicida visando o controle da ferrugem asiática não foi eficiente nessa pesquisa. Embora alguns trabalhos realizados no continente africano tenham comprovado a necessidade de até três pulverizações (10), no presente estudo, porém, apenas uma pulverização fungicida, independente do estádio fenológico da cultura, foi suficiente para promover produtividade significativamente superior ao tratamento testemunha e estatisticamente igual aos tratamentos com duas aplicações. Os resultados deste trabalho evidenciaram que a pulverização fungicida contra $P$. pachyrhizi é indispensável para diminuir as perdas na produtividade provocadas pela doença e que, em algumas situações, apenas uma pulverização fungicida no estádio $R_{2}$ pode evitar perdas significativas na produtividade. No entanto, devem-se levar em consideração as condições ambientais de cada região, pressão da doença, tecnologia de aplicação de fungicidas, variedade utilizada, ingrediente ativo do fungicida e custos do controle.

\section{REFERÊNCIAS BIBLIOGRÁFICAS}

1. Aguiar-júnior, H.O.; Raetano, C.G.; Prado, E.P.; Dal Pogetto, M.H.F.A.; Christovam, R.S.; Gimenes, M.J. Adjuvantes e assistência de ar em pulverizador de barras sobre a deposição da calda e controle de Phakopsora pachyrhizi (Sydow \& Sydow) Summa Phytopathologica, Botucatu, v.37, n.3, p.103-109, 2011.

2. Bonde , M.R.; Melching, J.S.; Bromfield, K.R. Histology of the suscept-pathogen relationship between Glycine max and Phakopsora pachyrhizi, the cause of soybean rust. Phytopathology,
Saint Paul, v.66, p.1290-1294, 1976.

3. Calvo E.S.; Kiihl, R.A.S; Garcia, A.; Harada, A.; Hiromoto, D.M. Two major recessive soybean genes conferring soybean rust resistance. Crop Science, Madison, v.48, p.1350-1354, 2008.

4. Campbell, C. L.; Madden, L. V. Introduction to plant disease epidemiology. New York: John Wiley, 1990. 532 p.

5. Christovam, R.S.; Raetano, C.G.; Prado, E.P.; Dal Pogetto, M.H.F.A.; Aguiar-Júnior, H.O.; Gimenes, M.J.; Serra, M.E. Airassistance and low volume application to control of Asian rust on soybean crop. Journal of Plant Protection Research, Poznan, v.50, n.3, p.354-359, 2010.

6. Cunha, J.P.A.R.; Moura, E.A.C.; Silva Júnior, J.; Zago, F.A.; Juliatti, F.C. Efeito de pontas de pulverização no controle químico da ferrugem da soja. Engenharia Agrícola, Jaboticabal, v.28, n.2, p.283-291, 2008.

7. Godoy, C.V.; Flausino, A.M.; Santos, L.C.M.; DEL Ponte, E.M. Eficiência e controle da ferrugem asiática da soja em função do momento de aplicação sob condições de epidemia em Londrina, PR. Tropical Plant Pathology, v.34, p.56-61, 2009.

8. Godoy, C.V.; Hoga, L.J.; Canteri, M.G. Diagrammatic scale for assessment of soybean rust severity. Fitopatologia Brasileira, Brasília, v.31, n.1, p.63-68, 2006.

9. Goellner, K.; Loehrer, M.; Conrath, U.; Koch, E.; Schaffrath, U. Phakopsora pachyrhizi, the causal agent of Asian soybean rust. Molecular Plant Pathology, Oxford, v.11, n.2, p.169-177, 2010.

10. Levy, C. Epidemiology and chemical control of soybean rust in southern Africa. Plant Disease, Saint Paul, v.89, p.669-674, 2005.

11. Mueller, T.A.; Miles, M.R.; Morel, W.; Marois, J.J.; Wright, D.L.; Kemerait, R.C.; Levy, C.; Hartman, G.L. Effect of fungicides and timing of application on soybean rust severity and yield. Plant Disease, Saint Paul, v.93, n.2, p.243-248, 2009.

12. Prado, E.P.; Raetano, C.G.; Aguiar Júnior, H.O.; Dal Pogetto, M.H.F.A.; Christovam, R.S.; Gimenes, M.J.; Araújo, D. Velocidade do ar em barra de pulverização na deposição da calda fungicida, severidade da ferrugem asiática e produtividade da soja. Summa Phytopathologica, Botucatu, v.36, n.1, p.45-50, 2010

13. Reis, E.F.; Lima Neto, V.C.; Godoy, C.V.; Rosa, C.T.; Castanho, H.E.; Vicente, N.G. Controle químico da ferrugem asiática da soja na região sul do Paraná. Scientia Agraria, Curitiba, v.8, n.3, p.319-323, 2007.

14. Walker, D.R.; Boerma, H.R.; Harris, D.K.; Phillips, D.V.; Schneider, R.W.; Hartman, G.L.; Miles, M.R.; Weaver, D.B.; Sikora, E.J.; Moore, S.H.; Buckley, J.B.; Shipe, E.R.; Mueller, J.D.; Wright, D.L.; Marois, J.J.; Nelson, R.L. Evaluation of USDA soybean germplasm accessions for resistance to soybean rust in the southern United States. Crop Science, Madison, v. 51, n.2, p.678$693,2011$. 